\title{
A VARIANT OF THE MOTOR BRANCH OF THE MEDIAN NERVE IN THE HAND
}

\author{
Basil T. Papathanassiou, Athens, Greece
}

Variations in the pattern of nerve supply to the hand are common and are of importance in hand surgery. A variant of the motor branch of the median nerve was recently observed twice, at dissection and again during an operation.

According to the usual descriptions (Quain 1895, Testut and Latarjet 1949, Hollinshead 1958, Gray 1962, Kaplan 1965), in the palm the median nerve divides into two parts, deep to and approximately at the distal border of the flexor retinaculum. In the majority of cases these subsequently give rise to four to five terminal branches. The motor (or recurrent) branch arises from the anterior surface of the lateral part, follows a short course laterally and supplies some of the thenar muscles. During this course it separates from its nerve of origin and passes around the distal border of the flexor retinaculum.

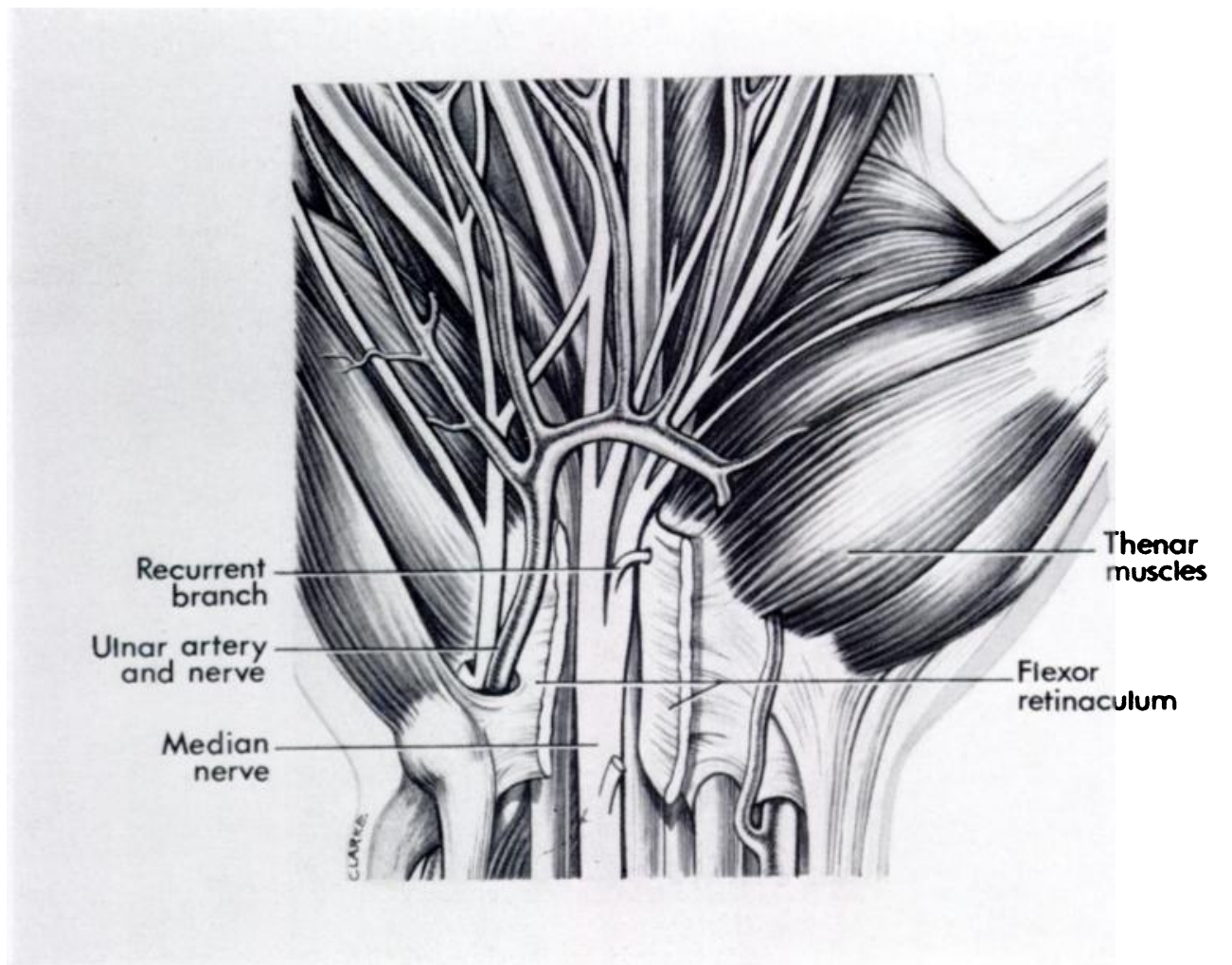

Fig. 1

Drawing of the specimen showing the course of the motor branch of the median nerve.

\section{ANATOMICAL SPECIMEN}

At dissection of a male right hand it was observed that the division of the median nerve occurred within the carpal tunnel. The motor branch arose from the antero-medial aspect of the lateral part, passed laterally and left the carpal tunnel by piercing the flexor retinaculum six millimetres proximal to its distal border (Fig. 1). 


\section{CASE REPORT}

A fifty-nine-year-old butcher presented with digital paraesthesia in the distribution of the right median nerve. He had also noticed weakness of the right thumb for some years. On examination there was total functional loss of the abductor pollicis brevis, and sensory signs of median nerve compression, which were far less significant than the severe motor loss.

Electromyography showed total denervation of the abductor pollicis brevis. At operation (Dr K. M. Backhouse) the motor branch of the median nerve was found to be reduced almost to a thread. It arose in the same manner as described in the preceding paragraph, and went through a very small opening in the flexor retinaculum. In view of the possibility of compression of the branch the retinaculum was divided and the branch decompressed. After operation the sensibility improved, but the motor function remained unchanged.

\section{COMMENT}

This variation, of which no mention could be found in previous reports (Rowntree 1949, Seddon 1954), would render the motor branch of the median nerve vulnerable during an operation for carpal tunnel decompression.

\section{SUMMARY}

A variation of the motor branch of the median nerve is described in which this branch arose more proximally and pierced the flexor retinaculum. Its significance during a carpal tunnel decompression is pointed out.

I wish to thank Dr K. M. Backhouse for his help and advice during the preparation of this paper and for kind permission to present his case. In addition I am grateful to him for allowing me the use of the facilities of the Department of Anatomy, Charing Cross Hospital Medical School.

\section{REFERENCES}

BACKHOUSE, K. M. (1966): Personal communication.

GraY, H. (1962): Gray's Anatomy: Descriptive and Applied. Thirty-third edition. Edited by D. V. Davies and F. Davies. London: Longmans.

Hollinshead, W. H. (1958): Anatomy for Surgeons. Volume 3. The Back and Limbs. London: Cassell \& Company Limited.

KaPlan, E. B. (1965): Functional and Surgical Anatomy of the Hand. Second edition. London: Pitman Medical Publishing Co. Ltd. Philadelphia: J. B. Lippincott Company.

QuaIN, J. (1895): Elements of Anatomy. Tenth edition. Edited by E. A. Schäfer and G. D. Thane. London: Longmans, Green \& Co.

Rowntree, T. (1949): Anomalous Innervation of the Hand Muscles. Journal of Bone and Joint Surgery, 31-B, 505.

Seddon, H. J., ed. (1954): Peripheral Nerve Injuries. Medical Research Council Special Report Series. No. 282. London: Her Majesty's Stationery Office.

Testut, L., and LatarJet, A. (1949): Traité d'Anatomie humaine. Volume 3. Ninth edition. Paris: G. Doinet Cie. 